\title{
Molecular detection of Mycoplasma genitalium in endocervical swabs and associated rates of macrolide and fluoroquinolone resistance in Hong Kong
}

\author{
Kevin KM Ng *, Patricia KL Leung, Terence KM Cheung
}

\section{A B S T R A C T}

Introduction: There is a global trend of increasing macrolide and fluoroquinolone resistance in Mycoplasma genitalium (MG), such that international guidelines recommend molecular detection of resistance if a patient has MG-positive test results. Tests for MG are not routinely performed in Hong Kong. This study examined the detection of $\mathrm{MG}$ in endocervical swabs and the associated macrolide and fluoroquinolone resistance rates.

Methods: Endocervical swabs received from two sexual health clinics in Hong Kong for routine assessments of Chlamydia trachomatis and Neisseria gonorrhoeae were also subjected to detection of MG. All MG-positive samples were tested for resistancemediating mutations in $23 \mathrm{~S}$ rRNA, parC, and gyrA genes. Laboratory records and past results for each patient were analysed.

Results: In total, endocervical swabs from 285 patients were included in this study. Mycoplasma genitalium was detected in swabs from 21 patients $(7.4 \%)$ by real-time polymerase chain reaction with a

This article was published on 10 Sep 2020 at www.hkmj.org. commercial kit. Among MG-positive samples which were successfully analysed further, macrolide resistance-mediating mutations in $23 \mathrm{~S}$ rRNA were

found in $42.1 \%$ (8/19); fluoroquinolone resistancerelated mutations in parC and gyr $A$ were found in $65 \%(13 / 20)$ and $0 \%(0 / 20)$, respectively. All macrolide-resistant MG strains were also fluoroquinolone-resistant $(42.1 \%, 8 / 19)$. No assessed factors were associated with the detection of MG or resistance-related mutations.

Conclusion: In Hong Kong, MG was detected in endocervical swabs from $7.4 \%$ of patients in sexual health clinics, with high rates of macrolide and fluoroquinolone resistance. These findings warrant careful review of testing, clinical correlation, and treatment strategies for MG in the context of increasing antibiotic resistance.

\section{Hong Kong Med J 2020;26:390-6 \\ https://doi.org/10.12809/hkmj208507}

KKM Ng *, MB, ChB, FRCPath

PKL Leung, MPhil

TKM Cheung, MPhil

Public Health Laboratory Services Branch, Centre for Health Protection,

Department of Health, Hong Kong SAR Government, Hong Kong

* Corresponding author: kevinkmng@yahoo.com.hk

New knowledge added by this study

Mycoplasma genitalium (MG) was detected in endocervical swabs from $7.4 \%$ of patients in two sexual health clinics in Hong Kong.

- High rates of macrolide and fluoroquinolone resistance-associated mutations ( $42.1 \%$ and $65 \%$, respectively) were detected in MG-positive specimens.

- All macrolide-resistant MG strains were also fluoroquinolone-resistant.

- No clinical or demographic factors were significantly associated with the detection of MG or resistance-related mutations.

Implications for clinical practice or policy

- Our findings support the existing recommendation that testing should be reserved only for patients with increased risks or for whom treatment has failed, as well as their contacts.

- The empirical uses of macrolide and fluoroquinolone regimens utilised in Hong Kong might explain the high rates of resistance found in this study.

- Careful review is required with respect to testing, clinical correlation, and treatment strategies for MG in the context of increasing antibiotic resistance.

\section{Introduction}

Mycoplasma genitalium (MG) is capable of causing urogenital infection, especially urethritis, in men. There is increasing evidence to support its ability to cause cervicitis and pelvic inflammatory disease in women. ${ }^{1}$ Data from a recent meta-analysis showed a prevalence of $1.3 \%$ in the general populations of developed countries, with similar rates among 
men and women; furthermore, the prevalence ranged from $0.6 \%$ to $12.6 \%$ in clinic-based studies. $^{2}$ In terms of therapy, macrolides such as azithromycin are considered first-line treatment, while fluoroquinolones (FQ) such as moxifloxacin are considered second-line treatment. However, antibiotic resistance is an emerging problem, with cited rates of macrolide and FQ resistance both reaching approximately $70 \%$ in the Asia-Pacific region. ${ }^{3}$ Consequently, in the context of increasing reports of treatment failure, ${ }^{4,5}$ multiple international guidelines indicate that all MG-positive specimens should be subjected to testing for macrolide resistance-mediating mutations and test-of-cure purposes. ${ }^{6-8}$

In Hong Kong, testing for MG is not routinely undertaken in the public sector. Notably, a cross-sectional study performed in 2008 in Hong Kong showed respective prevalences of $10 \%$ and $2 \%$ in symptomatic and asymptomatic men who sought sexual health services. ${ }^{9}$ Empirical treatment for non-gonococcal urethritis or non-specific genital tract infection encompassing MG infection generally comprises either a single dose of azithromycin or a 1-week course of doxycycline. Data regarding resistance profiles in Hong Kong are not available. This laboratory-based study aimed to determine the prevalences of MG in both symptomatic and asymptomatic women attending sexually transmitted infection (STI) clinics, as well as to determine the rates of macrolide and FQ resistance in MG-positive endocervical swabs, by using molecular methods.

\section{Methods}

\section{Specimen and data collection}

From March to May 2019, endocervical swabs of female patients sent from two STI clinics in Hong Kong for routine molecular detection of Chlamydia trachomatis (CT) and Neisseria gonorrhoeae (NG) were also subjected to detection of MG. Information regarding the presence or absence of genitourinary symptoms was provided by attending physicians. All available laboratory information for each tested patient was reviewed to determine demographic data, history of STI, human immunodeficiency virus status, and test results from the current visit.

\section{Detection of Mycoplasma genitalium}

The cobas TV/MG assay (Roche Diagnostics, Rotkreuz, Switzerland) performed on the cobas 6800 System (Roche Diagnostics) was used for detection of MG. The cobas TV/MG assay is a CE-marked, Food and Drug Administrationcleared, commercial qualitative nucleic acid test that utilises the real-time polymerase chain reaction for dual detection of Trichomonas vaginalis (TV) and MG. Its reported overall sensitivity and specificity

\section{香港子宮頸內拭子中生殖道支原體的分子檢測以 及相關大環內酯類和氟喹諾酮類藥物耐藥比率}

\author{
吳景文、梁嘉玲、張健文
}

引言：生殖器支原體中出現大環內酯類和氟喹諾酮類藥物耐藥在全球 有上升趨勢。因此, 不少國際指引均建議生殖器支原體檢測呈陽性的 患者進行耐藥分子檢測。現時, 香港沒有推行生殖器支原體定期檢 測。本研究檢視子宮頸內拭子中生殖器支原體的檢測以及相關的大環 內酯類和氟喹諾酮類藥物耐藥比率。

方法：對香港兩家性病檢測診所收集的子宮頸內拭子進行沙眼衣原體 和淋病奈瑟氏菌常規分子檢測, 以及生殖器支原體檢測。生殖器支原 體檢測為陽性的樣本會進行 $23 S$ rRNA、parC和 $g y r A$ 基因耐藥介導突變 檢測，並為每名患者的實驗室記錄及過往檢測結果進行分析。

結果：納入285名患者的子宮頸內拭子樣本。利用市售的即時聚合酶 連鎖反應套裝於 21 名患者 $(7.4 \%)$ 中檢測到生殖器支原體。根據進一 步的生殖器支原體陽性樣本分析, 於 $23 \mathrm{~S}$ rRNA基因中發現大環內酯類 耐藥介導突變佔 $42.1 \%$ （8/19）；而 par $C$ 和 $g y r A$ 基因中發現與氟喹諾 酮類耐藥相關突變分別佔65\%（13/20）和0\%（0/20）。所有大環內 酯耐藥的生殖器支原體菌株也呈氟喹諾酮耐藥 $(42.1 \%, 8 / 19)$, 以 及沒有發現與生殖器支原體或耐藥相關突變的檢測相關的評估因素。

結論：香港性病檢測診所有 $7.4 \%$ 患者的子宮頸內拭子檢出生殖器支原 體, 對大環內酯和氟喹諾酮類藥物的耐藥率很高。這些結果值得在增 加抗生素耐藥性的背景下仔細審視生殖器支原體測試、臨床相關性和 治療策略。

rates were $83.1 \%$ and $98.4 \%$, respectively, for MG detection in endocervical swabs from female patients. ${ }^{10}$ Tests were performed in accordance with the manufacturer's instructions.

\section{Detection of other sexually transmitted pathogens}

In brief, $\mathrm{CT}$ and NG were detected by the cobas CT/NG assay (Roche Diagnostics), while herpes simplex virus (HSV) 1 and HSV 2 were detected by the cobas HSV 1 and 2 assay (Roche Diagnostics), both performed on the cobas 4800 System (Roche Diagnostics). In addition, NG was detected by the culture method on modified Thayer-Martin agars. Either molecular- or culture-based test indicating the presence of NG was considered a positive result. Trichomonas vaginalis was detected by the cobas TV/MG assay (Roche Diagnostics) and wet mount microscopy after enrichment in Feinberg medium. Similar to NG, either test indicating the presence of TV was considered a positive result. Syphilis was detected by serological tests of serum specimens, including enzyme immunoassay (DiaSorin, Saluggia, Italy), Venereal Disease Research Laboratory test (Becton, Dickinson and Company, Franklin Lakes [NJ], US), fluorescent treponemal antibody absorption test (ImmunoDiagnostics Limited, Hong Kong, China), or Treponema pallidum passive particle agglutination test (Fujirebio Diagnostics AB, Göteborg, Sweden). 


\section{Detection of macrolide and fluoroquinolone resistance}

Mutations at nucleotide positions 2071 and 2072 (2058 and 2059, respectively, by Escherichia coli numbering) of the 23S rRNA gene have been associated with macrolide resistance in MG and subsequent treatment failure ${ }^{11,12}$; mutations in the quinolone resistance-determining region of the parC gene, and possibly the gyrA gene, have been associated with FQ resistance..$^{5}$ Polymerase chain reaction analysis of these genes was performed as described previously. ${ }^{13,14}$ Sequencing was performed using a 3730xl DNA Analyzer (Applied Biosystems, Foster City [CA], US), in accordance with the manufacturer's instructions. Primers used for sequencing were the same as those used for the polymerase chain reaction. Resulting sequences were compared to the sequence of wild-type strain MG G37 by using BLAST (https://blast.ncbi.nlm. nih.gov/Blast.cgi).

\section{Statistical analysis}

Calculation of odds ratios, and the Chi squared test or Fisher's exact test, were performed as univariate analysis to identify associations between assessed factors (ie, age, previous STI clinic visit, history of STI, symptoms, and sexually transmitted co-infections) and outcomes (ie, detection of MG and detection of resistance mutations), as well as between STI and symptoms. Because of the low outcome frequency, Firth logistic regression was employed to analyse associations between factors with $\mathrm{P}<0.25$ in univariate analysis and the detection of resistance mutations. IBM SPSS Statistics Subscription (Windows version, IBM Corp, Armonk [NY], US) was used for data analysis.

The STROBE statement reporting guidelines were followed in this study.

\section{Results}

In total, 285 non-duplicated specimens from 285 patients were included in this study. The mean patient age was 35.5 years (range, 16-76 years); $23.9 \%$ of the patients $(n=68)$ were in the younger age-group ( $\leq 25$ years). Of the 285 patients, $59.6 \%$ ( $n=170$ ) were new patients without a previous relevant testing record. In all, $18.9 \%$ of the patients $(n=54)$ had a documented history of STI. None were known human immunodeficiency virus carriers; however, human immunodeficiency virus status was not available for seven patients. Regarding the current clinic visit, $60.7 \%$ of the patients $(n=173)$ were symptomatic, and $7.4 \%(\mathrm{n}=21)$ had MG-positive test results (14 specimens exhibited MG alone; 7 specimens exhibited MG and another pathogen). Table 1 shows the numbers of STIs detected among these 285 patients.
TABLE I. Sexually transmitted infections detected among 285 patients in Hong Kong

\begin{tabular}{lcc}
\hline $\begin{array}{l}\text { Sexually } \\
\text { transmitted } \\
\text { infection }\end{array}$ & $\begin{array}{c}\text { No. of patients } \\
\text { with positive } \\
\text { results }\end{array}$ & $\begin{array}{c}\text { No. of symptomatic } \\
\text { patients with } \\
\text { positive results }\end{array}$ \\
\hline MG & 14 & 10 \\
MG, CT & 5 & 4 \\
\hline MG, TV & 2 & 2 \\
\hline CT & 27 & 22 \\
\hline TV & 15 & 8 \\
\hline SYP & 11 & 3 \\
\hline NG & 4 & 3 \\
\hline HSV 1 or 2 & 4 & 3 \\
\hline CT, TV & 3 & 3 \\
\hline NG, SYP & 3 & 3 \\
\hline CT, NG & 2 & 2 \\
\hline NG, TV & 1 & 1 \\
\hline CT, NG, TV & 1 & 1 \\
\hline Negative & 193 & 108 \\
\hline Total & 285 & 173 \\
\hline Ab & 3 & 3 \\
\hline
\end{tabular}

Abbreviations: $\mathrm{CT}=$ Chlamydia trachomatis; $\mathrm{HSV}=$ herpes simplex virus; $M G=$ Mycoplasma genitalium; NG = Neisseria gonorrhoeae; SYP = syphilis;TV = Trichomonas vaginalis

Younger age, previous STI clinic visit, history of STI, symptoms, and sexually transmitted co-infections were not associated with the detection of MG (Table 2). Symptoms were only significantly associated with the detection of CT (Table 3).

Among the 21 MG-positive endocervical swabs, sequencing results for $23 \mathrm{~S}$ rRNA were available for 19 specimens. In total, $42.1 \%$ of the specimens $(\mathrm{n}=8)$ harboured the macrolide resistancemediating mutations A2071G or A2072G. Regarding $\operatorname{par} C$ and $\operatorname{gyr} A$, sequencing results were available for 20 specimens. Overall, $65 \%$ of the specimens $(\mathrm{n}=13)$ harboured the FQ resistance-related mutations G248T (Ser83Ile), G259T (Asp87Tyr), or G259A (Asp87Asn) within parC; no mutations were detected in $g y r A$. Among the 19 specimens with sequencing results available regarding both macrolide and FQ resistance, dual resistance was detected in $42.1 \%$ of the specimens $(n=8)$; thus, all macrolide-resistant strains were also resistant to FQ. Furthermore, C184T (Pro62Ser) in parC, for which clinical significance is unknown, was detected in one specimen without any other mutation and in one specimen with dual resistance.

In subgroup analysis of patients with MG-positive specimens, younger age, previous STI clinic visit, symptoms, and sexually transmitted co-infections were not associated with the detection of resistance mutations, similar to the findings among all specimens; however, a history of STI was 
TABLE 2. Univariate analysis of risk factors for detection of Mycoplasma genitalium and detection of resistance mutation in Mycoplasma genitalium-positive specimens

\begin{tabular}{|c|c|c|c|c|}
\hline \multirow[t]{2}{*}{ Characteristic } & \multicolumn{2}{|c|}{ Detection of MG } & \multicolumn{2}{|c|}{$\begin{array}{l}\text { Detection of resistance mutations in } \\
\text { MG-positive specimens }\end{array}$} \\
\hline & Odds ratio $(95 \% \mathrm{Cl})$ & $P$ value & Odds ratio $(95 \% \mathrm{Cl})$ & $P$ value \\
\hline Age $\leq 25$ years & $0.997(0.351-2.83)$ & 0.996 & $0.9(0.115-7.031)$ & 1 \\
\hline Previous STI clinic visit & $0.903(0.362-2.253)$ & 0.827 & $0.18(0.026-1.236)$ & 0.164 \\
\hline Previous STI & $1.371(0.479-3.922)$ & 0.555 & $0.083(0.007-0.982)$ & 0.047 \\
\hline Symptomatic & $2.181(0.776-6.132)$ & 0.131 & $0.321(0.029-3.556)$ & 0.606 \\
\hline Co-infection & $1.359(0.527-3.505)$ & 0.524 & $0.109(0.014-0.872)$ & 0.056 \\
\hline
\end{tabular}

Abbreviations: $95 \% \mathrm{Cl}=95 \%$ confidence interval; $\mathrm{MG}=$ Mycoplasma genitalium; STI = sexually transmitted infection

TABLE 3. Association between sexually transmitted infections and symptoms

\begin{tabular}{lcc}
\hline \multirow{2}{*}{$\begin{array}{l}\text { Sexually transmitted } \\
\text { infection }\end{array}$} & \multicolumn{2}{c}{ Presence of symptoms } \\
\cline { 2 - 3 } & Odds ratio (95\% Cl) & P value \\
\hline MG & $2.181(0.776-6.132)$ & 0.131 \\
CT & $4.009(1.618-9.937)$ & 0.001 \\
TV & $1.424(0.526-3.611)$ & 0.455 \\
SYP & $0.467(0.158-1.384)$ & 0.161 \\
NG & $6.81(0.86-54)$ & 0.055 \\
HSV 1 or 2 & $1.959(0.201-19.07)$ & 1 \\
\hline
\end{tabular}

Abbreviations: $95 \% \mathrm{Cl}=95 \%$ confidence interval; $\mathrm{CT}=$ Chlamydia trachomatis; $\mathrm{HSV}=$ herpes simplex virus; MG = Mycoplasma genitalium; NG = Neisseria gonorrhoeae; SYP = syphilis; TV = Trichomonas vaginalis

negatively associated with the detection of mutations (Table 2). This association did not remain after multivariable logistic regression (odds ratio $=0.151$, $95 \%$ confidence interval $=0.004-2.983, \mathrm{P}=0.221$ ).

\section{Discussion}

In this study, $7.4 \%$ of endocervical swabs from women attending STI clinics exhibited MG-positive results, although no assessed factors were obviously associated with the detection of MG. Mycoplasma genitalium-positive rates did not significantly differ $(\mathrm{P}=0.131)$ among patients who were symptomatic (9.2\%) and those who were asymptomatic (4.5\%). These rates were comparable with the findings of the aforementioned 2008 cross-sectional study in Hong Kong involving male patients with STI, ${ }^{9}$ as well as with the findings of a multicentre clinical study in the US. ${ }^{15}$ Reported rates of MG detection have exhibited considerable variability. A 2018 systematic review ${ }^{2}$ revealed that higher rates were prevalent among at-risk groups (eg, commercial sex workers and men who have sex with men), in clinic-based settings, and in countries with lower economic development. In
Australia, the prevalence of MG was found to range from $2.1 \%$ to $13 \%$, depending on the population tested $^{16}$; while a higher prevalence of approximately $15 \%$ has been reported in Japan. ${ }^{17}$ Nevertheless, the prevalence in the general population and asymptomatic patients remained low (1.3\%), ${ }^{2}$ which did not support universal screening. In the present study, symptoms were not associated with the detection of MG. Considering the organism's uncertain clinical significance and natural history, it is necessary to balance the need to test and the risks of unnecessary treatment, including potential aggravation of antibiotic resistance. We agree with the existing recommendation that testing should be carefully selected, reserved only for patients with increased risks or for whom treatment has failed, as well as their contacts. ${ }^{18}$

Importantly, the choice of specimen might affect the detection of MG. A recent prospective, multicentre study showed that self or cliniciancollected vaginal swabs exhibited the best sensitivities (92\%-98.9\%), while urinary and endocervical swabs were less sensitive ( $81.5 \%$ and $77.8 \%$, respectively). ${ }^{15}$ These findings were consistent with the results of prior studies ${ }^{19-21}$; notably, some studies found that endocervical swabs were more sensitive than urinary specimens, ${ }^{20,21}$ presumably because of the lower bacterial load in urine. ${ }^{22}$ Endocervical swabs are the routine specimens sent to our laboratory from STI clinics for molecular detection of CT and NG; we perform assays for detection of MG and CT, as recommended by European guidelines. ${ }^{6}$ Of note, the relatively low sensitivity of the test with respect to endocervical swabs might also have underestimated the prevalence of MG in our study.

Resistance-related mutations in 23S rRNA and parC genes were detected in $42.1 \%$ and $65 \%$ of MG-positive samples, respectively, among which none harboured mutations in gyrA. All macrolideresistant strains were also FQ-resistant (42.1\%). Although the populations have differed among studies, similarly high rates of macrolide resistance 
TABLE 4. Mycoplasma genitalium macrolide and fluoroquinolone resistance rates in different regions of the world ${ }^{3,23-28}$

\begin{tabular}{|c|c|c|c|c|c|}
\hline & \multirow[t]{2}{*}{ Population } & \multicolumn{3}{|c|}{ Resistance rate (\%) } & \multirow[t]{2}{*}{ Reference } \\
\hline & & Macrolide & $\mathbf{F Q}$ & Dual & \\
\hline Hong Kong & Female & 42.1 & 65 & 42.1 & Current study \\
\hline Japan & Male & 42.2 & 53.1 & 12.5 & Hamasuna et $\mathrm{al}^{23}$ \\
\hline Japan & Symptomatic male & $>70$ & $60-70$ & $\sim 50$ & Deguchi et $\mathrm{al}^{3}$ \\
\hline Australia & STI clinic attendees & 62 & 10.5 & 7.8 & Sweeney et $\mathrm{al}^{24}$ \\
\hline New Zealand & Community/STI clinic attendees & 75 & 22 & 20 & Vesty et $\mathrm{al}^{25}$ \\
\hline United States & Diverse clinic attendees & 48.3 & NA & NA & Getman et $\mathrm{al}^{26}$ \\
\hline United States & MSM with HIV & 74.1 & 32 & 24 & Dionne-Odom et $\mathrm{al}^{27}$ \\
\hline Europe & Heterogeneous & $>50$ & $\sim 5$ & NA & Fernández-Huerta et al ${ }^{28}$ \\
\hline
\end{tabular}

Abbreviations: $\mathrm{FQ}=$ fluoroquinolone; $\mathrm{HIV}=$ human immunodeficiency virus; MSM = men who have sex with men; $\mathrm{NA}=$ not available

have been reported, while rates of FQ and dual resistance have varied among regions (Table 4).,323-28 Several studies also demonstrated consistent increases in resistance rates over time. . $^{3,28,29}$

All mutations detected in this study have been described previously; while C184T (Pro62Ser) in $\operatorname{parC}$ is of unknown significance, others are known to confer antibiotic resistance leading to higher minimal inhibitory concentrations and treatment failure. ${ }^{5,11,12,23}$ In particular, the extent of FQ resistance is reportedly related to the presence of concurrent $\operatorname{parC}$ and $g y r A$ mutations. Although MG strains with lone $\operatorname{par} C$ mutations had reduced susceptibilities to FQ, they were able to be eradicated by sitafloxacin and (possibly) moxifloxacin. However, concurrent gyrA mutations have been shown to further increase the FQ minimal inhibitory concentrations, leading to treatment failure. ${ }^{23,30}$

No assessed factors were significantly associated with the detection of MG in this study, possibly due to the limited number of positive samples. The authors of other studies have suggested that a syndromic approach (ie, management of a patient whereby a syndrome is used as a basis for the treatment of the causative organisms) and the use of a single dose of azithromycin for treatment of NG (as part of dual therapy), non-gonococcal urethritis/non-specific genital tract infection, or known MG infection contribute to the emergence of macrolide resistance in MG, because this regimen is suboptimal and might exert selective pressure on resistant strains. ${ }^{28,29,31}$ A similar phenomenon has been observed with respect to $\mathrm{FQ}$, especially in Japan, where frequent use of the second-line antibiotic sitafloxacin caused selection of resistant strains, leading to high rates of FQ resistance in MG.3 In public clinics in Hong Kong, a single dose of azithromycin or a 1-week course of doxycycline is used as empirical treatment for non-gonococcal urethritis or non-specific genital tract infection. If no culprit pathogen is identified and the patient complains of persistent symptoms during follow-up, a 1-week course of moxifloxacin for possible MG is considered, following exclusion of other causes (eg, non-compliance). These empirical uses of macrolide and FQ regimens might explain the high rates of resistance found in this study. For other regions with lower rates of FQ resistance, the relationship between FQ use and emergence of its resistance in MG requires further investigation.

In the context of increasing drug resistance, international guidelines have suggested follow-up molecular testing for resistance determinants in MG-positive specimens. ${ }^{6-8}$ In particular, the most recent British and Australian guidelines include revised treatment regimens, which suggest 1 week of doxycycline followed by 3 days of azithromycin as treatment for macrolide-sensitive (or susceptibility unknown) MG, or followed by 7 to 10 days of moxifloxacin as treatment for macrolide-resistant MG. ${ }^{7,8}$ Alternative antibiotics that might be effective (eg, pristinamycin) require further evaluation. ${ }^{32,33}$

When the detection of MG and its drug resistance profile is considered after patient selection and careful review of clinical indications, testing at a private laboratory may be sought, because this service is not readily available in the public sector in Hong Kong. Our findings of high macrolide and FQ resistance rates in MG implied that the use of azithromycin and moxifloxacin as empirical firstand second-line therapies, respectively, might be ineffective; furthermore, this approach could induce greater drug resistance. These findings should be taken into consideration in future assessments of treatment guidelines for Hong Kong. The acquisition of updated treatment strategies from international guidelines may also be useful.

Because our laboratory is a reference laboratory 
that serves all public STI clinics in Hong Kong, our database is comprehensive in terms of laboratory testing records. Specimens in this study were unique and not duplicated for any patient. In addition, we have considerable capacity to perform arrays of confirmatory tests for various sexually transmitted pathogens. However, this study was limited by the absence of other clinical information such as sexual practices, antimicrobials prescribed, and treatment outcomes, because these data were not available to the authors. The small number of MG-positive samples also limited our ability to assess correlations with factors considered in this study.

\section{Conclusion}

Mycoplasma genitalium was detected in $7.4 \%$ of 285 endocervical swabs collected from both symptomatic and asymptomatic women attending STI clinics in Hong Kong. Among the MG-positive samples, macrolide resistance-mediating mutations and fluoroquinolone resistance-related mutations were detected in $42.1 \%$ and $65 \%$, respectively. Dual resistance was also detected in all macrolideresistant strains $(42.1 \%)$. These findings suggest that both testing and treatment strategies require careful review to avoid further enhancing the prevalence of antibiotic resistance.

\section{Author contributions}

Concept or design: KKM Ng, PKL Leung.

Acquisition of data: All authors.

Analysis or interpretation of data: All authors.

Drafting of the manuscript: KKM Ng.

Critical revision of the manuscript for important intellectual content: All authors.

All authors had full access to the data, contributed to the study, approved the final version for publication, and take responsibility for its accuracy and integrity.

\section{Conflicts of interest}

All authors have disclosed no conflicts of interest.

\section{Acknowledgement}

The authors acknowledge the excellent work and contributions by staff at the Special Investigation Laboratory of Public Health Laboratory Services Branch, Centre for Health Protection, Department of Health, Hong Kong SAR Government.

\section{Funding/support}

This research received no specific grant from any funding agency in the public, commercial, or not-for-profit sectors.

\section{Ethics approval}

This study obtained ethics approval (Ref LM 424/2019) from the Ethics Committee of the Department of Health, Hong Kong SAR Government. Patients consented to testing for sexually transmitted pathogens.

\section{References}

1. Lis R, Rowhani-Rahbar A, Manhart LE. Mycoplasma genitalium infection and female reproductive tract disease: a meta-analysis. Clin Infect Dis 2015;61:418-26.

2. Baumann L, Cina M, Egli-Gany D, et al. Prevalence of Mycoplasma genitalium in different population groups: systematic review and meta-analysis. Sex Transm Infect 2018;94:255-62.

3. Deguchi T, Ito S, Yasuda M, et al. Surveillance of the prevalence of macrolide and/or fluoroquinolone resistanceassociated mutations in Mycoplasma genitalium in Japan. J Infect Chemother 2018;24:861-7.

4. Lau A, Bradshaw CS, Lewis D, et al. The efficacy of azithromycin for the treatment of genital Mycoplasma genitalium: a systematic review and meta-analysis. Clin Infect Dis 2015;61:1389-99.

5. Murray GL, Bradshaw CS, Bissessor M, et al. Increasing macrolide and fluoroquinolone resistance in Mycoplasma genitalium. Emerg Infect Dis 2017;23:809-12.

6. Jensen JS, Cusini M, Gomberg M, Moi H. 2016 European guideline on Mycoplasma genitalium infections. J Eur Acad Dermatol Venereol 2016;30:1650-6.

7. Australasian Sexual Health Alliance. Australian STI management guidelines for use in primary care. Available from: http://www.sti.guidelines.org.au/sexuallytransmissible-infections/mycoplasma-genitalium. Accessed 15 Mar 2020.

8. Soni S, Horner P, Rayment M, et al. British Association for Sexual Health and HIV national guideline for the management of infection with Mycoplasma genitalium (2018). Int J STD AIDS 2019;30:938-50.

9. Yu JT, Tang WY, Lau KH, et al. Role of Mycoplasma genitalium and Ureaplasma urealyticum in nongonococcal urethritis in Hong Kong. Hong Kong Med J 2008;14:125-9.

10. US Food and Drug Administration. cobas TV/MG Premarket Notification 510(k). Table 34. Available from: https://www.accessdata.fda.gov/cdrh_docs/pdf19/ K190433.pdf. Accessed 15 Mar 2020.

11. Jensen JS, Bradshaw CS, Tabrizi SN, Fairley CK, Hamasuna R. Azithromycin treatment failure in Mycoplasma genitalium-positive patients with nongonococcal urethritis is associated with induced macrolide resistance. Clin Infect Dis 2008;47:1546-53.

12. Bissessor M, Tabrizi SN, Twin J, et al. Macrolide resistance and azithromycin failure in a Mycoplasma genitaliuminfected cohort and response of azithromycin failures to alternative antibiotic regimens. Clin Infect Dis 2015;60:1228-36.

13. Peuchant O, Ménard A, Renaudin H, et al. Increased macrolide resistance of Mycoplasma pneumoniae in France directly detected in clinical specimens by real-time PCR and melting curve analysis. J Antimicrob Chemother 2009;64:52-8.

14. Shimada Y, Deguchi T, Nakane K, et al. Emergence of clinical strains of Mycoplasma genitalium harbouring alterations in ParC associated with fluoroquinolone resistance. Int J Antimicrob Agents 2010;36:255-8.

15. Gaydos CA, Manhart LE, Taylor SN, et al. Molecular testing for Mycoplasma genitalium in the United States: results from the AMES Prospective Multicenter Clinical Study. J Clin Microbiol 2019;57:e01125-19.

16. Trevis T, Gossé M, Santarossa N, Tabrizi S, Russell D, 
McBride WJ. Mycoplasma genitalium in the Far North Queensland backpacker population: an observational study of prevalence and azithromycin resistance. PLoS One 2018;13:e0202428.

17. Hamasuna R. Mycoplasma genitalium in male urethritis: diagnosis and treatment in Japan. Int J Urol 2013;20:67684.

18. Stewart JD, Webb BQ, Francis M, Graham M, Korman TM. Should we routinely test for Mycoplasma genitalium when testing for other sexually transmitted infection? Med J Aust 2020;212:30-1.

19. Jensen JS, Björnelius E, Dohn B, Lidbrink P. Comparison of first void urine and urogenital swab specimens for detection of Mycoplasma genitalium and Chlamydia trachomatis by polymerase chain reaction in patients attending a sexually transmitted disease clinic. Sex Transm Dis 2004;31:499507.

20. Wroblewski JK, Manhart LE, Dickey KA, Hudspeth MK, Totten PA. Comparison of transcription-mediated amplification and PCR assay results for various genital specimen types for detection of Mycoplasma genitalium. J Clin Microbiol 2006;44:3306-12.

21. Lillis RA, Nsuami MJ, Myers L, Martin DH. Utility of urine, vaginal, cervical, and rectal specimens for detection of Mycoplasma genitalium in women. J Clin Microbiol 2011;49:1990-2.

22. Murray GL, Danielewski J, Bodiyabadu K, et al. Analysis of infection loads in Mycoplasma genitalium clinical specimens by use of a commercial diagnostic test. J Clin Microbiol 2019;57:e00344-19.

23. Hamasuna R, Le PT, Kutsuna S, et al. Mutations in ParC and GyrA of moxifloxacin-resistant and susceptible Mycoplasma genitalium strains. PLoS One 2018;13:e0198355.

24. Sweeney EL, Trembizki E, Bletchly C, et al. Levels of Mycoplasma genitalium antimicrobial resistance differ by both region and gender in the state of Queensland, Australia: implications for treatment guidelines. J Clin
Microbiol 2019;57:e01555-18.

25. Vesty A, McAuliffe G, Roberts S, Henderson G, Basu I. Mycoplasma genitalium antimicrobial resistance in community and sexual health clinic patients, Auckland, New Zealand. Emerg Infect Dis 2020;26:332-5.

26. Getman D, Jiang A, O'Donnell M, Cohen S. Mycoplasma genitalium prevalence, coinfection, and macrolide antibiotic resistance frequency in a multicenter clinical study cohort in the United States. J Clin Microbiol 2016;54:2278-83.

27. Dionne-Odom J, Geisler WM, Aaron KJ, et al. High prevalence of multidrug-resistant Mycoplasma genitalium in human immunodeficiency virus-infected men who have sex with men in Alabama. Clin Infect Dis 2018;66:7968.

28. Fernández-Huerta M, Barberá MJ, Serra-Pladevall J, et al. Mycoplasma genitalium and antimicrobial resistance in Europe: a comprehensive review. Int J STD AIDS 2020;31:190-7.

29. Martens L, Kuster S, de Vos W, Kersten M, Berkhout H, Hagen F. Macrolide-resistant Mycoplasma genitalium in southeastern region of the Netherlands, 2014-2017. Emerg Infect Dis 2019;25:1297-303.

30. Murray GL, Bodiyabadu K, Danielewski J, et al. Moxifloxacin and sitafloxacin treatment failure in Mycoplasma genitalium infection: association with parC mutation G248T (S83I) and concurrent gyrA mutations. J Infect Dis 2020;221:1017-24.

31. Horner P, Ingle SM, Garrett F, et al. Which azithromycin regimen should be used for treating Mycoplasma genitalium? A meta-analysis. Sex Transm Infect 2018;94:14-20.

32. Bradshaw CS, Jensen JS, Waites KB. New horizons in Mycoplasma genitalium treatment. J Infect Dis 2017;216:S412-9.

33. Read TR, Jensen JS, Fairley CK, et al. Use of pristinamycin for macrolide-resistant Mycoplasma genitalium infection. Emerg Infect Dis 2018;24:328-35. 